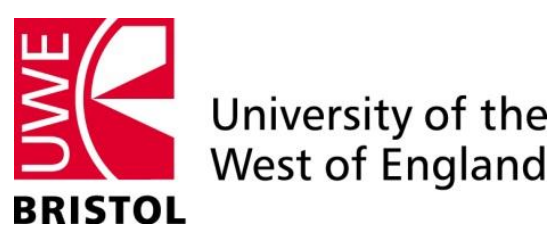

Faculty of Business and Law

\title{
Estimating regional input coefficients and multipliers: The use of the FLQ is not a gamble
}

\author{
Anthony T. Flegg \\ Department of Accounting, Economics and Finance, \\ University of the West of England, Bristol, UK \\ and Timo Tohmo \\ Jyväskylä University School of Business and Economics, \\ University of Jyväskylä, Finland
}

(Revised version: 27/11/2013)

Economics Working Paper Series

1302 


\title{
Estimating Regional Input Coefficients and Multipliers: The Use of the FLQ is not a Gamble
}

\author{
Anthony T. Flegg* and Timo Tohmo** \\ * Department of Accounting, Economics and Finance, University of the West of England, \\ Bristol, Coldharbour Lane, Bristol BS16 1QY, UK \\ Email: tony.flegg@uwe.ac.uk \\ ** Jyväskylä University School of Business and Economics, PO Box 35, \\ FI-40014 University of Jyväskylä, Finland \\ Email: timo.tohmo@jyu.fi
}

(Revised version 27/11/2013)

\begin{abstract}
This paper re-examines the Finnish evidence presented by Lehtonen and Tykkyläinen on the use of location quotients (LQs) in estimating regional input coefficients and multipliers. They argue that the choice of an LQ-based method is a gamble and that there is no single method that can be recommended for general use. It is contended here that this evidence is erroneous and that the FLQ yields results far superior to those from competing formulae, so it should provide a satisfactory way of generating an initial set of input coefficients. The choice of a value for the parameter $\delta$ is also examined.

Regional input-output tables Finland FLQ formula Location quotients Multipliers JEL classifications: C67, O18, R15
\end{abstract}




\section{INTRODUCTION}

Thanks to the work of STATISTICS FINLAND (2000, 2006), which has produced detailed input-output tables for Finland and its twenty regions for both 1995 and 2002, analysts have been able to evaluate the relative performance of several alternative non-survey techniques. Two investigations of this kind stand out: a study by FLEGG and TOHMO (2013b), who employed data for 1995, and one by LEHTONEN and TYKKYLÄINEN (2012), who used figures for 2002. In both cases, the authors used alternative formulae based on location quotients (LQs) to regionalize the national tables. However, the findings were very different: Flegg and Tohmo found that the FLQ (Flegg's location quotient) was by far the most successful way of generating estimates of regional input coefficients and multipliers, whereas Lehtonen and Tykkyläinen concluded that, at least to some extent, the choice of a regionalization formula was a gamble. The primary aim of this comment is to attempt to reconcile these conflicting findings.

The rest of the paper is structured as follows. The next section is concerned with the role of LQs in the regionalization process. This is followed by an examination of Lehtonen and Tykkyläinen's methodology. In the subsequent two sections, a reworked set of results for sectoral output multipliers and input coefficients is presented. The problem of choosing an appropriate value for the parameter $\delta$ is then considered. This is followed by a comparison of the data sets for 1995 and 2002. The role of regional characteristics is discussed in the penultimate section and the final section concludes.

\section{LOCATION QUOTIENTS}

Location quotients (LQs) are a popular way of regionalizing national input-output tables, especially in the initial stages. For this purpose, the following alternative LQs are often used:

$$
\mathrm{SLQ}_{i} \equiv \frac{\mathrm{RE}_{i} / \mathrm{TRE}}{\mathrm{NE}_{i} / \mathrm{TNE}} \equiv \frac{\mathrm{RE}_{i}}{\mathrm{NE}_{i}} \times \frac{\mathrm{TNE}}{\mathrm{TRE}}
$$




$$
\mathrm{CILQ}_{i j} \equiv \frac{\mathrm{SLQ}_{i}}{\mathrm{SLQ}_{j}} \equiv \frac{\mathrm{RE}_{i} / \mathrm{NE}_{i}}{\mathrm{RE}_{j} / \mathrm{NE}_{j}}
$$

where $\mathrm{SLQ}_{i}$ is the simple $\mathrm{LQ}, \mathrm{CILQ}_{i j}$ is the cross-industry $\mathrm{LQ}, \mathrm{RE}_{i}$ is regional employment (or output) in supplying sector $i$ and $\mathrm{NE}_{i}$ is the corresponding national figure. $\mathrm{RE}_{j}$ and $\mathrm{NE}_{j}$ are defined analogously for purchasing sector $j$. TRE and TNE are the respective regional and national totals. Some authors, including Lehtonen and Tykkyläinen, also make use of Round's formula, which is defined as follows:

$$
\mathrm{RLQ}_{i j} \equiv \mathrm{SLQ}_{i} /\left[\log _{2}\left(1+\mathrm{SLQ}_{j}\right)\right]
$$

The properties of these conventional formulae are explored by several authors; see, for example, FlegG and Webber (1997, 2000), Bonfiglio and Chelli (2008), FlegG and TOHMO (2013b), and MiLLER and BLAIR (2009, pp. 349-358).

So long as no aggregation of sectors in the national input-output table is required, the following simple formula can be used to convert national into regional input coefficients:

$$
r_{i j}=\beta_{i j} \times a_{i j}
$$

where $r_{i j}$ is the regional input coefficient, $\beta_{i j}$ is an adjustment coefficient and $a_{i j}$ is the national input coefficient. $r_{i j}$ measures the amount of regional input $i$ needed to produce one unit of regional gross output $j$; it thus excludes any supplies of $i$ 'imported' from other regions or obtained from abroad. $a_{i j}$ likewise excludes any supplies of $i$ obtained from abroad. The role of $\beta_{i j}$ is to take account of a region's purchases of input $i$ from other regions in the nation.

If we replace $\beta_{i j}$ in equation (4) with an LQ, we can obtain estimates of the $r_{i j}$. Thus, for instance:

$$
\hat{r}_{i j}=\mathrm{CILQ}_{i j} \times a_{i j}
$$

Note: No adjustment is made to the national coefficient where CILQ $\mathrm{C}_{i j} \geq 1$ and likewise for the other LQs.

However, there is abundant empirical evidence that demonstrates how the conventional 
LQs tend to underestimate imports from other regions and hence tend to overstate regional multipliers (BONFIGLIO and CHELl, 2008; FLEGG and TOHMO, 2013b). One reason for this understatement of regional trade by the conventional LQs is that they either preclude crosshauling, as with the SLQ, or fail to take sufficient account of this common phenomenon, as with the CILQ (FLEGG and TOHMO, 2013a).

FLEGG et al. (1995) attempted to overcome this underestimation of interregional trade via their FLQ formula. In its refined form (FLEGG and WEBBER, 1997), the FLQ is defined as:

$$
\begin{aligned}
& \mathrm{FLQ}_{i j} \equiv \mathrm{CILQ}_{i j} \times \lambda^{*} \quad \text { for } i \neq j \\
& \mathrm{FLQ}_{i j} \equiv \mathrm{SLQ}_{i} \times \lambda^{*} \quad \text { for } i=j
\end{aligned}
$$

where:

$$
\lambda^{*} \equiv\left[\log _{2}(1+\mathrm{TRE} / \mathrm{TNE})\right]^{\delta}
$$

It is assumed that $0 \leq \delta<1$; as $\delta$ increases, so too does the allowance for interregional imports. $\delta=0$ represents a special case where $\mathrm{FLQ}_{i j}=\mathrm{CILQ}_{i j}$. As with other LQ-based formulae, the FLQ is constrained to unity.

Two aspects of the FLQ formula are worth emphasizing: its cross-industry foundations and the explicit role attributed to regional size. Thus, with the FLQ, the relative size of the regional purchasing and supplying sectors is considered when determining the adjustment for interregional trade. This is a feature that the CILQ and FLQ share. However, by also taking explicit account of the relative size of a region, the FLQ should help to address the problem of cross-hauling, which is more likely to be prevalent in smaller regions than in larger ones. Smaller regions are apt to be more open to interregional trade.

A sizable body of empirical evidence now demonstrates that the FLQ can produce much better results than the SLQ and CILQ. This evidence includes, for instance, case studies of Scotland (FlegG and WeBber, 2000), Finland (ToHmo, 2004; FlegG and ToHMO, 2013b), 
Germany (KowAlEwSKI, 2013) and Argentina (FlEGG et al., 2014). Furthermore, Bonfiglio and ChELLi (2008) carried out a Monte Carlo simulation of 400,000 output multipliers. Here the FLQ clearly outperformed its predecessors in terms of generating the best estimates of these multipliers. This Monte Carlo study is discussed in detail by FLEGG and TOHмO, 2013b, along with some of the studies mentioned above.

\section{METHODOLOGY}

The first stage in Lehtonen and Tykkyläinen's study involved aggregating the transactions for fifty-nine national sectors, so that they corresponded to the twenty-six sectors available for each of the twenty Finnish regions. The resulting national input coefficients, the $a_{i j}$, were then regionalized by applying, in turn, four alternative LQ-based formulae, namely the SLQ, CILQ, RLQ and FLQ. This procedure generated four alternative sets of estimates of the $r_{i j}$. In the case of the FLQ, Lehtonen and Tykkyläinen used the values of $\delta$ shown in their appendix A. The same procedure was adopted here.

Lehtonen and Tykkyläinen employed the following statistical criteria to assess the accuracy of the estimated multipliers: ${ }^{1}$

$$
\begin{gathered}
\mathrm{STPE}=100 \Sigma_{j}\left|\hat{m}_{j}-m_{j}\right| / \Sigma_{j} m_{j} \\
\mathrm{MWAE}=\Sigma_{j} w_{j}\left|\hat{m}_{j}-m_{j}\right| \\
\mathrm{U}^{\mathrm{S}}=\left\{\operatorname{sd}\left(\hat{m}_{j}\right)-\operatorname{sd}\left(m_{j}\right)\right\}^{2} / \mathrm{MSE} \\
\mathrm{U}^{\mathrm{M}}=\left\{\mathrm{m}\left(\hat{m}_{j}\right)-\mathrm{m}\left(m_{j}\right)\right\}^{2} / \mathrm{MSE}
\end{gathered}
$$

where $\hat{m}_{j}$ is the estimated type I output multiplier for sector $j$ (column sum of the LQ-based Leontief inverse matrix) in a given region, $m_{j}$ is the corresponding benchmark value from Statistics Finland, $w_{j}$ is the proportion of regional employment in sector $j, \operatorname{sd}()$ is the standard deviation and $\mathrm{m}(\mathrm{)})$ is the mean. STPE and MWAE denote the standardized total percentage 
error and mean weighted absolute error, respectively. The mean squared error is defined as follows:

$$
\operatorname{MSE}=(1 / n) \Sigma_{j}\left(\hat{m}_{j}-m_{j}\right)^{2}
$$

where $n=26$ is the number of sectors.

The selection of an appropriate set of statistical criteria to evaluate the results is an important issue, so it is worth examining the approach taken by Lehtonen and Tykkyläinen. At the outset, they examined a set of seventeen statistics that have been used by various authors but then eliminated five of them on a priori grounds (LEHTONEN and TYKKYLÄINEN, 2012, p. 5). For instance, three statistics were eliminated on the grounds that they would tend to reward methods that tended to overstate the input coefficients. The correlation coefficient was rejected on the basis that it would not necessarily capture the closeness of the $\hat{r}_{i j}$ and the $r_{i j}$. A fifth statistic was eliminated because it would tend to place undue emphasis on avoiding any very large errors. All of these decisions seem entirely reasonable.

Of the remaining twelve statistics, LEHTONEN and TYKKYLÄINEN (2012, p. 5) chose four that 'did not correlate strongly with any other selected statistics and had some high correlations with those that were not selected'. However, it could be argued that this focus on correlations runs the risk of not paying enough attention to the underlying properties of the statistics under consideration and to their potential usefulness to analysts. For instance, $\mathrm{U}^{\mathrm{M}}$ measures the proportion of the MSE attributable to a difference in means, whereas $\mathrm{U}^{S}$ measures the proportion due to a difference in standard deviations. ${ }^{2}$ It is unclear why the size of these proportions should matter. Furthermore, if both $\mathrm{U}^{\mathrm{M}}$ and $\mathrm{U}^{\mathrm{S}}$ declined, there would be a concomitant rise in the relative importance of the covariance component of the MSE, yet there is no obvious reason why that would be desirable. It would seem better, therefore, to measure the size of the gap between the means and standard deviations independently of the MSE, as in the following formulae: 


$$
\begin{aligned}
& \tilde{\mathrm{U}}^{\mathrm{S}}=\left\{\operatorname{sd}\left(\hat{m}_{j}\right)-\operatorname{sd}\left(m_{j}\right)\right\}^{2} \\
& \tilde{\mathrm{U}}^{\mathrm{M}}=\left\{\mathrm{m}\left(\hat{m}_{j}\right)-\mathrm{m}\left(m_{j}\right)\right\}^{2}
\end{aligned}
$$

It could also be argued that basing the evaluation on only four statistics is unnecessarily restrictive and that it would be desirable to consider the following measures as well:

$$
\begin{aligned}
\mathrm{MPE} & =(100 / n) \Sigma_{j}\left(\hat{m}_{j}-m_{j}\right) / m_{j} \\
\mathrm{U} & =100 \sqrt{\frac{\sum_{j}\left(\hat{m}_{j}-m_{j}\right)^{2}}{\sum_{j} m_{j}^{2}}}
\end{aligned}
$$

The mean percentage error (MPE) has an obvious logic and doesn't overlap with any of the other statistics. It was not included in the original set of seventeen measures that Lehtonen and Tykkyläinen considered but it is employed by FLEGG and TOHMO (2013b), so its inclusion here would facilitate comparisons. Finally, U is Theil's well-known inequality coefficient, which has the merit that it encompasses both bias and variance (THEIL et al., 1966). Taken as a whole, the six different statistics considered above should suffice to capture the key characteristics of interest to analysts, which are likely to include bias, dispersion, the absolute and relative size of errors, the relative size of sectors and so on.

Having calculated the values of statistics (9) to (12) for each of the four LQ-based methods for each of the twenty regions, Lehtonen and Tykkyläinen then ranked each outcome from 1 (best) to 4 (worst). On this basis, a neutral method should generate a mean rank of 2.5, whereas above-average and below-average methods should score under 2.5 and over 2.5, respectively. In terms of probability, a mean rank of 1.5 or less would be statistically significant at the $5 \%$ level.

\section{RESULTS FOR MULTIPLIERS}

Table 1 near here 
Lehtonen and Tykkyläinen's results are reproduced in Table $1 .^{3}$ We can see that the FLQ attains an overall mean rank of 2.01, followed by the SLQ with 2.63, the RLQ with 2.65 and the CILQ with 2.71. The FLQ is clearly the best method on average, although the outcomes are statistically significant at the $5 \%$ level in only six regions. The conventional techniques are all well behind the FLQ, yet there is not a great deal of difference between them in terms of overall performance.

Table 2 near here

However, when the computations were redone using the same approach as Lehtonen and Tykkyläinen, the very different pattern exhibited in Table 2 emerged. ${ }^{4}$ The FLQ now has a mean rank of unity in thirteen regions and an overall mean of 1.30. Kainuu, Etelä-Pohjanmaa and Uusimaa are the only regions for which the FLQ is not the dominant technique and all but three of the mean ranks are statistically significant at the 5\% level. Although the conventional LQs are all well behind the FLQ, it is noteworthy that the SLQ is now clearly in second place, the RLQ in third place and the CILQ in last place. It is evident that the reworking has produced much larger gaps in the relative performance of the different techniques.

When Lehtonen and Tykkyläinen's results were examined in detail, using the data kindly provided by the authors, the main cause of the discrepancies was identified: their use of a different aggregated national transactions matrix. As noted above, it was necessary to aggregate the transactions for the fifty-nine national sectors, to produce a sectoral classification that corresponded to the twenty-six sectors available for each of the twenty Finnish regions. Using exactly the same sectoral classification, it was not possible to derive their aggregated matrix from the published Finnish national input-output tables. ${ }^{5}$

Table 3 near here

Whilst the use of ranks is a convenient way of summarizing a set of statistical outcomes that are measured in different units, it does have a serious shortcoming in terms of the loss of 
information concerning the gaps in performance. This point is illustrated in Table 3, which reveals that there is a very large gap across the board in the performance of the FLQ vis-à-vis the conventional LQs. If we ignore the outcomes for the $\tilde{U}^{S}$, the results strongly confirm that the SLQ is the second-best method. The CILQ and RLQ yield very similar results, which are inferior to those for the FLQ and SLQ.

Although Table 3 shows that the FLQ is demonstrably the best method according to all six criteria, it is worth checking to see how similar the different measures really are. The relevant correlations are displayed in Table 4.

Table 4 near here

Table 4 shows that the MPE has minimal correlation with the existing four statistics; it is, therefore, a very useful addition to the set of criteria. The other new measure, U, does exhibit a significant (at the 5\% level) correlation with STPE but it is less correlated with the other measures. Taken as a whole, the statistics do not overlap to a great extent and the fact that the FLQ performs very well according to all of them attests to the FLQ's versatility.

\section{RESULTS FOR COEFFICIENTS}

Even though most analysts are apt to be more concerned with the outcomes for regional sectoral multipliers, it is often fruitful to examine the results for the regional input coefficients, the $r_{i j}$, as well. At the outset, we shall consider a reworked set of results comparable with those discussed earlier for output multipliers. The calculations are based on the following formulae:

$$
\begin{aligned}
\mathrm{STPE} & =100 \Sigma_{i j}\left|\hat{r}_{i j}-r_{i j}\right| / \Sigma_{i j} r_{i j} \\
\mathrm{MWAE} & =(1 / n) \Sigma_{j} w_{j} \Sigma_{i}\left|\hat{r}_{i j}-r_{i j}\right| \\
\tilde{\mathrm{U}}^{\mathrm{S}} & =\left\{\operatorname{sd}\left(\hat{r}_{i j}\right)-\operatorname{sd}\left(r_{i j}\right)\right\}^{2} \\
\tilde{\mathrm{U}}^{\mathrm{M}} & =\left\{\mathrm{m}\left(\hat{r}_{i j}\right)-\mathrm{m}\left(r_{i j}\right)\right\}^{2}
\end{aligned}
$$


The findings are displayed in Table 5.

Table 5 near here

Coefficients are far more difficult to estimate accurately than multipliers and this fact is reflected in the statistics. For instance, for the FLQ, the mean value of the STPE across all regions is $5.8 \%$ for multipliers but $49.2 \%$ for coefficients. Even so, the same ranking of methods emerges for coefficients and multipliers: FLQ first, SLQ second, RLQ third and CILQ last. Moreover, the FLQ's overall mean rank is almost identical for coefficients (1.31) and multipliers (1.30).

\section{Table 6 near here}

The overall performance of the methods, using a broader range of criteria and cardinal rather than ordinal measures, is summarized in Table 6. The two additional criteria, the MPE and Theil's inequality coefficient $U$, bolster the impression one gains from the rankings that the FLQ is the most accurate method, with the SLQ in a creditable second place. ${ }^{6}$ The MPE is alone in judging the CILQ to be superior to the SLQ. However, if we were to choose the SLQ instead of the FLQ, we would be opting for a method that appears to generate estimates of the $r_{i j}$ that are both more biased and more dispersed. This assertion is confirmed by the respective values of $\tilde{U}^{\mathrm{M}}$ and $\tilde{U}^{\mathrm{S}}$, along with the fact that Theil's $U$ statistic, which captures both bias and variance, is lower for the FLQ than for the SLQ. Indeed, the SLQ is inferior to the FLQ in terms of all six criteria.

\section{Table 7 near here}

A strikingly different picture emerges from Lehtonen and Tykkyläinen's results, which are reproduced in Table 7. In terms of overall mean ranks, the FLQ is now in third place, with the SLQ first and the RLQ second. The CILQ remains in last place. These findings appear odd inasmuch as one might anticipate broadly similar rankings for coefficients and multipliers (see, for example, FLEGG and TOHMO, 2013b, tables 4 and 7; KOWALEWSKI, 2013, tables 3 and 4) and this is certainly not so for Lehtonen and Tykkyläinen's results (cf. 
Tables 1 and 7). It is the results for $\mathrm{U}^{\mathrm{S}}$ that are the most odd: whereas Table 7 shows an excellent performance by the FLQ, Table 1 displays a mediocre one. Furthermore, one might expect the rankings given by $\mathrm{U}^{\mathrm{M}}$ to be similar to those awarded by the STPE and MWAE, yet this is not so in Table 7. There are, therefore, several reasons why Lehtonen and Tykkyläinen's findings with regard to coefficients lack credibility.

\section{CHOOSING A VALUE FOR $\delta$}

Using an appropriate value for $\delta$ is crucial to the successful application of the FLQ formula. LEHTONEN and TYKKYLÄINEN (2012, p. 4) pursue a novel solution to the problem of selecting such a value. Their starting point is the original version of the FLQ formula (FLEGG et al., 1995):

$$
\begin{gathered}
\mathrm{FLQ}_{i j} \equiv \mathrm{CILQ}_{i j} \times \lambda^{\beta} \text { for } i \neq j \\
\mathrm{FLQ}_{i j} \equiv \mathrm{SLQ}_{i} \times \lambda^{\beta} \quad \text { for } i=j
\end{gathered}
$$

where:

$$
\lambda^{\beta} \equiv\left[(\mathrm{TRE} / \mathrm{TNE}) /\left\{\log _{2}(1+\mathrm{TRE} / \mathrm{TNE})\right\}\right]^{\beta}
$$

They then make use of the fact that TOHMO (2004) obtained an estimate of $\beta=1$ for the Keski-Pohjanmaa (K-P) region in 1995. Given $\beta=1$, they equate expressions (24) and (8) to derive the following formula for $\delta$ :

$$
\delta=\frac{\log \left[(\mathrm{TRE} / \mathrm{TNE}) /\left\{\log _{2}(1+\mathrm{TRE} / \mathrm{TNE})\right\}\right]}{\log \left[\log _{2}(1+\mathrm{TRE} / \mathrm{TNE})\right]}
$$

However, this is a formula for the ratio $\delta / \beta$ and not one for $\delta$ itself - except in the special case of the K-P region in 1995, where we may assume that $\beta=1$. If $\delta$ varies across regions, then logically so too must $\beta$, so formula (25) cannot be correct in general.

Nevertheless, the values of $\delta$ derived by LEHTONEN and TYKKYLÄINEN (2012, appendix A) do appear to yield sensible results in most cases and it is important to understand why this is so. The main explanation is the relatively low value of $\beta=1$ that was assumed, along with 
the fact that equation (25) guarantees that the value of $\delta$ will rise with regional size, TRE/TNE.

To afford a way of obtaining estimates of $\delta$, FLEGG and TOHMO (2013b) estimated the following regression equation for Finnish regions in 1995:

$$
\ln \delta=-1.8379+0.33195 \ln R+1.5834 \ln P-2.8812 \ln I+e
$$

where $R$ is regional size measured in terms of output and expressed as a percentage; $P$ is a survey-based estimate of each region's propensity to import from other regions, divided by the mean value of this propensity for all regions; $I$ is a survey-based estimate of each region's average use of intermediate inputs (including inputs imported from other regions), divided by the corresponding national proportion of intermediate inputs; $e$ is a residual. ${ }^{7}$

LEHTONEN and TYKKYLÄINEN (2012, p. 4) argue that the use of equation (26) would be problematic owing to the difficulty of obtaining data for $P$ and $I$. Even so, a well-informed analyst, who felt that the region under consideration did not diverge significantly from the norm in terms of $P$ and $I$, could set $P=I=1$ and make use of the following truncated equation to estimate $\delta$ :

$$
\ln \delta=-1.8379+0.33195 \ln R
$$

Lehtonen and Tykkyläinen assert that this would be 'definitely incorrect' because the intercept and slope of equation (27) would differ from the values that would be obtained from a simple regression (ibid.). However, the coefficients from a simple regression would be biased, unlike those from equation (27), which doesn't suffer from bias due to omitted variables. Lehtonen and Tykkyläinen's assertion fails to distinguish between an assumption that $P=I=1$ for a given region and the omission of $\ln P$ and $\ln I$ from the regression.

Equation (26) can, in fact, be rewritten in the following alternative form, which may be more convenient in some cases:

$$
\ln \delta=0.8167+0.33195 \ln R+1.5834 \ln p-2.8812 \ln I+e
$$


where $p$ is an estimate of each region's propensity to import from other regions, measured in terms of gross output. ${ }^{8}$ The advantage of this formulation is that the analyst would only need to estimate $p$, which might be an easier task than estimating the ratio $P$ in equation (26). As for $I$, the assumption of a unitary value could be retained. $P=1$ should be a good approximation in many cases.

What factors are likely to determine the value of $p$ ? Clearly, geographic distances and transportation costs between regions would play an important role in determining the mix of intraregional and interregional trade. For instance, the prohibitive cost of transporting goods from southern regions such as Uusimaa to remote northern regions such as Lappi (Finnish Lapland) is likely to promote self-sufficiency in these more remote regions. Here it is worth mentioning that an attempt to proxy the remoteness of a region by measuring its distance, $D$, from Helsinki produced a negligible $t$ statistic when $\ln D$ was added to the regression. This outcome is probably due to the fact that the effect of distance from Helsinki has already been absorbed into the variable $P$.

A rather different route to the estimation of $\delta$ has been proposed by Bonfiglio (2009), who derived the following regression equation:

$$
\hat{\delta}=0.994 P R O P-2.819 R S R P
$$

where $P R O P$ is the propensity to interregional trade and $R S R P$ is the relative size of regional purchases. Notwithstanding differences in definition, $P R O P$ is conceptually similar to $p$ in equation (28). RSRP is likewise analogous to $R$ and it is, therefore, a proxy for regional size. ${ }^{9}$

A problem with this approach is that the theoretical constraint $0 \leq \delta<1$ is not imposed on equation (29), as it is on equation (28), so it can, therefore, yield negative values of $\delta$ for regions that are relatively large or exhibit below-average propensities to import from other regions or both. Cases in point are Uusimaa in Finland and Baden-Wuerttemberg in Germany. ${ }^{\mathbf{1 0}}$ In addition, unlike the more general equation (28), Bonfiglio's regression does 
not allow for any differences in the degree of intermediation.

One caveat does, however, need to be mentioned in connection with equation (28): the equation was fitted to data for Finnish regions in 1995 and it's unclear whether the results would carry over to other contexts. Most crucially, the positive estimated elasticity of $\delta$ with respect to $R$ reflects the fact that, for this particular data set, some of the largest regions required relatively high values of $\delta$, whereas some of the smaller ones needed relatively low values (FLEGG and ToHmo, 2013b, table 3). Although more research clearly needs to be undertaken to establish whether the same pattern would occur elsewhere, the limited amount of evidence that does exist is encouraging. ${ }^{11}$

\section{COMPARISON OF 1995 AND 2002 DATA SETS}

An important issue now needs to be considered: to what extent are the data sets for 1995 and 2002 comparable? This issue is highlighted by the fact that FLEGG and TOHMO (2013b) found that the data set for 1995 was characterized by a central value of $\delta \approx 0.25$, whereas LEHTONEN and TYKKYLÄINEN (2012, p. 9) report that the use of this single value for all regions in 2002 generated extremely poor results for the FLQ. To explore this issue, an optimal value of $\delta$, denoted by $\delta^{*}$, was estimated for each region in 2002. The results are displayed in Table 8.

Table 8 near here

The first column of Table 8 shows the optimal values derived by FLEGG and TOHMO (2013b) for 1995, using the criterion of minimum MPE. ${ }^{\mathbf{1 2}}$ Apart from the fact that employment rather than output was used to measure regional size, the same procedure was adopted to derive the optimal values for 2002 shown in the second column. It is readily apparent that there has been a big reduction in the values of $\delta^{*}$ between 1995 and 2002 for all regions. Indeed, for Uusimaa, $\delta^{*} \approx 0 .{ }^{13}$ As before, there is also considerable interregional variation in the values of $\delta^{*}$. Looking at Table 8 , it is unsurprising that the use of $\delta=0.25$ for 
all regions in 2002 produced such unsatisfactory results.

Table 9 near here

How can we explain the differences between 1995 and 2002? One possibility is that the lower values of $\delta^{*}$ are indicative of a genuine fall in the amount of interregional trade and hence rise in the size of the regional multipliers. This is certainly what is suggested at first sight by the figures in Table 9. However, there are several grounds for questioning this interpretation. In the first place, it seems unlikely that regional self-sufficiency would increase to such a marked extent in the space of only seven years. Secondly, as explained below, there is no evidence of a rise in the size of the multipliers at a national level. Finally, the regional tables for 2002 were constructed in a very different way from those for 1995 and it is possible that some of the interregional trade was missed as a result.

The Finnish national input-output tables for 1995 and 2002 contain thirty-seven and fifty-nine sectors, respectively, although two of the latter sectors were amalgamated. ${ }^{14}$ To provide a way of comparing these tables, the weighted mean type I output multiplier, $\overline{\mathrm{K}}$, was computed for each year. Using employment weights, $\overline{\mathrm{K}}$ was found to be 1.5938 in 1995 and 1.6381 in 2002 . Using output weights, the corresponding figures were 1.6636 and 1.6731 . This closeness in the size of the multipliers across years is in sharp contrast with the large differences observed at the regional level.

Because the regional and national tables for 1995 are based on a common set of thirtyseven sectors, no aggregation of the national data was required prior to regionalization. By contrast, for 2002, it was necessary to aggregate the transactions data for the fifty-eight national sectors to obtain a classification corresponding to the twenty-six regional sectors. To assess the overall impact of this aggregation, $\overline{\mathrm{K}}$ was recomputed for the twenty-six aggregated national sectors. It is reassuring that $\overline{\mathrm{K}}$ changed only marginally, from 1.6381 to 1.6322 (using employment weights), and from 1.6731 to 1.6686 (using output weights), 
which suggests that minimal aggregation bias was introduced, while confirming the similarity of the national multipliers for 1995 and 2002.

The Finnish regional input-output tables for 1995 are unusual in the sense that they were constructed on the basis of a large-scale survey of over 9600 establishments in manufacturing, construction and services (KAUPPILA, 1999). The final response rate was $44.8 \%$, which represented $61.7 \%$ in terms of turnover (ibid., table 2). The survey-based data were augmented by information obtained from other sources, e.g. transportation statistics (KAUPPILA, 1999). In addition, more than 2500 wholesale establishments were surveyed and this survey was backed up by meetings with the largest companies (ibid.). Statistics Finland's study appears to have been carried out extremely thoroughly in terms of planning, execution and analysis, yet errors due to non-response bias, in particular, cannot be avoided in such an exercise. ${ }^{\mathbf{1 5}}$

By contrast, the regional tables for 2002 were constructed by integrating existing data on sales of industrial products with transportation statistics. LOUHELA (2006) points out that the industrial output statistics record the value, selling location and weight of products, and cover $90 \%$ of the mining, quarrying and manufactured goods produced in Finland, while the transportation statistics capture freight flows via road, rail, air and water. A problem with using freight flows is that the value of goods being exported from one region to another has to be inferred from their weight. Additional errors are bound to be introduced owing to the different monetary values of goods within the same broad classification (ibid.).

Although each methodological approach discussed above has its particular merits and demerits, what is important is whether these methodological differences can explain the contrasting results displayed in Table 9 for 1995 and 2002. Here it is interesting to note a finding by LOUHELA (2006), who reworked the earlier results by adopting the methodology used in the later study. He found that the value of trade flows, when estimated using 
industrial output statistics, was only $€ 54.2$ billion, whereas total sales from the survey were estimated to be $€ 60.5$ billion, which represents a difference of about $10 \%$ (ibid.). This finding suggests that the use of industrial output statistics in the construction of the 2002 tables might have caused an understatement of the volume of interregional trade.

To conclude, it is evident that there are large and systematic differences between the Finnish regional tables for 1995 and 2002. Although a case could be made for the use of either set of tables as a benchmark, the present authors' opinion is that, on balance, the 1995 survey-based regional tables are more satisfactory. A corollary of this is that the regression model (26), which is based on data for 1995, should generate more realistic values of $\delta$ than could be obtained from a new regression model based on data for 2002.

\section{REGIONAL CHARACTERISTICS}

LEHTONEN and TYKKYLÄINEN (2012, p. 2) set out to explore whether 'certain [LQ-based] formulae might be better suited to pick up particular regional attributes'. In doing so, they focus on the following measures (ibid., pp. 7-8):

- Herfindahl's index of specialization $(H)$

- Theil's index of specialization $(T)$

- Distance from Helsinki $(D)$

The authors find a highly significant correlation of $-0.790(p<0.001)$ between the mean ranks of the SLQ and FLQ, as recorded in Table 1, and suggest that this shows that the two methods 'may be suitable for different kinds of regions and could thus be used to complement each other as alternative techniques to achieve the best fit over all the regions' (ibid., pp. 10-11). They then attempt, via a correlation analysis, to link the ranks achieved by the two methods to the regional attributes listed above. The results are displayed in Table 10.

Table 10 near here 
Table 10 reveals that the SLQ ranks are negatively correlated with $H, T$ and $D$, whereas the FLQ ranks are positively correlated with these variables. In the light of these correlations, the authors suggest that the SLQ might be a more appropriate technique than the FLQ for peripheral regions and for those that exhibit a high degree of specialization (cf. ibid., p. 11). However, there are several reasons why one should be cautious in pursuing this suggestion.

The first reason is that none of these correlations is statistically significant at the $5 \%$ level, although the correlation between $H$ and the SLQ ranks comes close to being so ( $p=$ 0.060). What is more, the correlations are invariably weaker when they are recalculated using data from Table 2. Secondly, the inverse relationship the authors found between the SLQ and FLQ ranks is largely attributable to the results for two regions, Kainuu and Uusimaa: using the data from Table 2, the correlation between the SLQ and FLQ ranks falls from $-0.673(p<0.001)$ to $-0.396(p=0.104)$ when these two regions are excluded from the analysis.

More fundamentally, the relatively poor performance of the FLQ in these two regions can probably be explained, to a great extent, by the use of too large a value for $\delta$, as can be verified from Table 8 (0.039 instead of 0.092 should be used for Kainuu, and zero rather than 0.244 for Uusimaa). As a result, the FLQ makes too large an allowance for imports from other regions, which causes it to perform relatively badly versus the SLQ.

It could be argued, therefore, that analysts should focus on choosing an appropriate value of $\delta$ to use in the FLQ rather than search for a different formula such as the SLQ to apply in specific regions. If the region in question were thought to be relatively self-sufficient - as a result of a high degree of specialization or a peripheral location - then a relatively low value of $\delta$ could be obtained by choosing a relatively low value of $P$ in equation (26) or $p$ in (28). ${ }^{\mathbf{1 6}}$ 


\section{CONCLUSION}

This paper has re-examined the findings of LEHTONEN and TYKKYLÄINEN (2012), who used Finnish national and regional data for 2002 to assess the relative performance of four alternative regionalization formulae based on location quotients, namely the FLQ, SLQ, CILQ and RLQ. This assessment was done using a set of four statistical criteria with different properties. The formulae were then ranked in terms of their performance. Lehtonen and Tykkyläinen found that the FLQ produced the best estimates of regional sectoral multipliers, when judged in terms of its overall mean rank across four criteria and twenty regions. The three conventional formulae generated very similar overall mean ranks, which were some way behind the score attained by the FLQ.

A merit of Lehtonen and Tykkyläinen's methodological approach is that the use of ranks makes it possible to assess the statistical reliability of the results. Using a 5\% test, they found that the mean ranks attained by the FLQ were significantly better than an average outcome in only six regions. The performance of the SLQ was significantly above average in four regions, the RLQ in two and the CILQ in none. For the remaining eight regions, no technique was significantly better than average.

However, a reworking of the calculations produced a very different set of results. Most importantly, the FLQ was found to yield significantly better mean ranks in seventeen regions and the SLQ in two. For one region, there was no statistically dominant technique. Furthermore, on a scale of 1 (best) to 4 (worst), the FLQ's overall mean rank improved from 2.01 to 1.30 . By contrast, the SLQ, RLQ and CILQ achieved overall mean scores of 2.58, 2.79 and 3.34, respectively. Although the SLQ outperformed the RLQ and CILQ, its overall mean score is very close to what one might expect from a neutral technique (one that is neither good nor bad). ${ }^{17}$

Lehtonen and Tykkyläinen also presented a set of comparable results for input 
coefficients, which suggested that the SLQ, rather than the FLQ, was the most accurate way of estimating coefficients. However, these findings are at variance with their results for multipliers. What is more, they are inconsistent with the findings of earlier studies, which typically yield broadly similar results for coefficients and multipliers. Indeed, a reworking of Lehtonen and Tykkyläinen's analysis gave overall mean ranks in exactly the same order for multipliers and coefficients, with the FLQ clearly in first place and the SLQ in second place.

Lehtonen and Tykkyläinen extended their analysis by correlating the mean rank attained by each method in each region with (i) alternative measures of specialization and (ii) the region's location (measured in terms of distance from Helsinki). On the basis of this analysis, along with a highly statistically significant negative correlation between the mean ranks attained by the FLQ and SLQ, they suggested that the SLQ might be a more appropriate technique than the FLQ for peripheral regions and for those that exhibited a high degree of specialization. However, on closer examination, the statistical underpinnings of this interesting suggestion were found to be rather weak. The authors also did not offer a rationale, couched in terms of the contrasting properties of the FLQ and SLQ, for their suggestion.

Lehtonen and Tykkyläinen argue that the choice of an LQ-based method is a gamble and that no single method can be recommended for general use. However, on the basis of the reappraisal undertaken here of their empirical work, along with the findings of earlier studies, it is hard to sustain this argument. Indeed, the available evidence indicates that the FLQ typically yields results far superior to those from competing formulae, so it should provide a satisfactory way of generating an initial set of input coefficients in most regions. ${ }^{\mathbf{1 8}}$

Even so, the difficulties inherent in choosing an appropriate value for the unknown parameter $\delta$ in the FLQ formula pose a serious challenge for analysts. Indeed, if an inappropriate value of $\delta$ is selected, the FLQ cannot be relied upon to yield the most 
satisfactory results for a particular region and it could even give inferior results to the SLQ. Therefore, in the present authors' view, future empirical work should seek to shed more light on what value or values of $\delta$ should be used in specific circumstances rather than continue to evaluate the relative merits of competing LQ-based formulae. It seems especially unfruitful to devote any more attention to the CILQ and RLQ, in view of their very poor performance, as demonstrated both in this study and elsewhere. In terms of future work, it would be interesting to see whether a firm basis could be found for using sector-specific values of $\delta$, where regional sectors are known to be characterized by different attributes (as is suggested by KOWALEWSKI, 2013).

Acknowledgements - The authors wish to express their appreciation to the anonymous referees, and to Peter Bradley, Artjoms Ivlevs, Julia Kowalewski, Tobias Kronenberg, Leo Mastronardi, Carlos Romero and Chris Webber, for their helpful suggestions, which led to substantial improvements in this paper.

\section{NOTES}

1. Lehtonen and Tykkyläinen do not, in fact, explicitly give formulae pertaining to multipliers, so it was necessary to adapt the expressions for coefficients given in their table 1.

2. Note that $\operatorname{MSE} \equiv\left\{\mathrm{m}\left(\hat{m}_{j}\right)-\mathrm{m}\left(m_{j}\right)\right\}^{2}+\left\{\operatorname{sd}\left(\hat{m}_{j}\right)-\operatorname{sd}\left(m_{j}\right)\right\}^{2}+2(1-r) \times \operatorname{sd}\left(\hat{m}_{j}\right) \times \operatorname{sd}\left(m_{j}\right)$, where $r$ is the correlation coefficient between $\hat{m}_{j}$ and $m_{j}$. Cf. THEIL et al., 1966, pp. 29-30.

3. See LEHTONEN and TYKKYLÄINEN (2012, table 4). The average rank attained by the FLQ in Ahvenanmaa is incorrect; it should be 2.00 and not 2.25. The results for $\mathrm{U}^{\mathrm{M}}$ are odd in the sense that the means are all well above unity, which is inconsistent with the properties of equation (12). This may have occurred because $n^{2}=676$ rather than $n=26$ was used as a divisor in the calculation of the MSE; see formula (13).

4. The use of $\tilde{U}^{\mathrm{S}}$ and $\tilde{U}^{\mathrm{M}}$ rather than $\mathrm{U}^{\mathrm{S}}$ and $\mathrm{U}^{\mathrm{M}}$ had a negligible impact on the rankings. 
5. Although the mean sectoral difference between Lehtonen and Tykkyläinen's figures for national transactions by aggregated sector and the true figures was a relatively small $2.0 \%$, some of the individual sectoral differences were substantial, with a range from $-24.2 \%$ to $+40.0 \%$. The mean absolute error was $7.3 \%$. Likewise, for the sectoral sums of intermediate inputs, the individual differences ranged from $-24.4 \%$ to $+31.5 \%$. The mean error was $0.6 \%$ and the mean absolute error was $6.4 \%$. Supporting calculations are available on request.

6. The MPE was estimated using the formula: MPE $=\left\{100 /\left(n^{2}-z\right)\right\} \Sigma_{i j}\left(\hat{r}_{i j}-r_{i j}\right) / r_{i j}$, where $z$ is the number of zero values of $r_{i j}$. Such cases were excluded from the calculations. A disadvantage of this measure, in the context of coefficients, is that it is inflated in situations where $r_{i j}$ is close to zero. This facet is illustrated by the relatively large values of MPE displayed in Table 6 .

7. Note that the propensity to import from other regions is expressed as a proportion of gross output. The mean value of this propensity for all twenty Finnish regions in 1995 was 0.1870 .

8. Notice that the intercept has changed by $-1.5834 \ln 0.187=2.6548$, where 0.187 is the sectoral mean propensity to import from other Finnish regions in 1995.

9. $P R O P$ is the proportion of a region's total intermediate inputs that is purchased from other regions, whereas $p$ in equation (28) is the proportion of a region's total gross output that is bought from other regions. $R S R P$ is the ratio of total regional to total national intermediate inputs. By contrast, $R$ in equation (28) measures regional size in terms of output or employment.

10. Using data from KowALEWSKI (2013, table 1), the following estimate of $\delta$ was derived for Baden-Wuerttemberg in 1993:

$$
\hat{\delta}=0.994 \times 0.205-2.819 \times 0.134=-0.174
$$

Here the state's share of total German employment (ibid., p. 5) has been used as a proxy for RSRP. An even more negative result was obtained for Uusimaa in 1995:

$$
\hat{\delta}=0.994 \times 0.3016-2.819 \times 0.2925=-0.525
$$

In this instance, the outcome reflects the fact that Uusimaa is by far the largest Finnish region. It also has the lowest value of $P R O P$. For the other nineteen regions, Bonfiglio's method generated the required positive values of $\hat{\delta}$. 
11. Using equation (28), along with data from KOWALEWSKI (2013, table 1 and p. 10), the following estimate of $\delta$ was derived for Baden-Wuerttemberg in 1993:

$$
\hat{\delta}=\exp (0.8169+0.33195 \ln 14.38+1.5834 \ln 0.1019-2.8812 \ln 0.9925)=0.151
$$

FLEGG and TOHMO (2013b) used the mean percentage error (MPE) to derive optimal values of $\delta$ for use in their regression and 0.151 is fairly close to the optimal value of $\delta=0.17$ that KOWALEWSKI (2013, table 3) obtained for multipliers when using the MPE (her $\mu_{4}$ statistic).

Some further evidence is furnished by FLEGG et al. (2014) for the province of Córdoba, Argentina. Using detailed survey-based regional data for 2003, they derived the following estimate of delta:

$$
\hat{\delta}=\exp (-1.8296+0.33195 \ln 8.27+1.5834 \ln 0.115-2.8812 \ln 0.421)=0.127
$$

Here the constant differs from that in the previous equation because the sectoral mean intermediate use for Córdoba $(0.421)$ has not been divided by the corresponding figure for Argentina. This had the effect of altering the constant by $2.8812 \ln 0.3991=-2.6465$, where 0.3991 is the sectoral mean ratio of intermediate use to gross output for Finland in 1995. This estimate of 0.127 is close to the optimal value of $\delta=0.120$ that FLEGG et al. (2014, table 2) derived for multipliers when using the MPE criterion.

12. The table shows, for each region, the value of $\delta$ yielding MPE $\approx 0$.

13. The use of $\delta=0.244$, rather than $\delta^{*} \approx 0$, in the calculations reported in Tables 2 and 5 for Uusimaa can explain the comparatively poor performance of the FLQ in that region. The fact that $\delta^{*} \approx 0$ for Uusimaa is a surprising outcome; it suggests that the CILQ (with SLQs down the principal diagonal of the adjustment matrix) is the best method and that no extra allowance for imports from other regions is required.

14. Sector 59 in the 2002 tables (Private households with employed persons) has no intermediate transactions, so it was aggregated with sector 58 (Other service activities).

15. The study commenced in June 1997, with the aim of collecting data pertaining to 1996. It was assumed that no change in trade flows had occurred between 1995 (the base year of the regional tables) and 1996 (KAUPPILA, 1999). 
16. It may be noted that $\ln H$ and $\ln D$ had near-zero $t$ ratios when they were added to regression (26). This finding suggests that these variables have minimal additional explanatory power and that the effects of location and specialization have already been allowed for via the inclusion of $\ln R, \ln P$ and $\ln I$.

17. It should be noted that the FLQ should only be applied to national input-output tables that exclude imports from abroad; where such imports are included, Kronenberg's CHARM method can be used for purposes of regionalization. The type of table that is used would depend on the aim of the study. The FLQ is suitable for estimating output and employment multipliers, whereas CHARM is suitable for estimating the supply multipliers of concern in environmental studies. See Kronenberg $(2009,2012)$ and FleGG and TOHMO (2013a).

18. These initial coefficients should always be evaluated by the analyst on the basis of informed judgement, surveys of selected industries, etc., rather than taken at face value. See FLEGG and TOHмO (2013b, p. 718).

\section{REFERENCES}

BONFIGLIO A. (2009) On the parameterization of techniques for representing regional economic structures, Economic Systems Research 21, 115-127.

Bonfiglio A. and Chelli F. (2008) Assessing the behaviour of non-survey methods for constructing regional input-output tables through Monte Carlo simulation, Economic Systems Research 20, $243-258$.

Flegg A. T., Mastronardi L. J. and Romero C. A. (2014) Empirical evidence on the use of the FLQ formula for regionalizing national input-output tables: the case of the province of Córdoba, Argentina, forthcoming working paper, University of the West of England, Bristol.

FlegG A. T. and Tohmo T. (2013a) A Comment on Tobias Kronenberg's "Construction of regional input-output tables using nonsurvey methods: the role of cross-hauling", International Regional Science Review 36, 235-257, first published on 13 June 2012 (OnLine First), doi: $10.1177 / 0160017612446371$. 
FLEGG A. T. and TOHMO T. (2013b) Regional input-output tables and the FLQ formula: a case study of Finland, Regional Studies 47, 703-721, first published on 25 August 2011 (iFirst), doi: 10.1080/00343404.2011.592138.

FlegG A. T. and WebBer C. D. (1997) On the appropriate use of location quotients in generating regional input-output tables: reply, Regional Studies 31, 795-805.

FlegG A. T. and WebBer C. D. (2000) Regional size, regional specialization and the FLQ formula, Regional Studies 34, 563-569.

FlegG A. T., Webber C. D. and Elliott M. V. (1995) On the appropriate use of location quotients in generating regional input-output tables, Regional Studies 29, 547-561.

KAUPPILA J. (1999) Estimating interregional trade flows in Finland 1996, paper presented at the $39^{\text {th }}$ Congress of the European Regional Science Association, Dublin, 23-27 August 1999.

KOWALEWSKI J. (2013) Regionalization of national input-output tables: empirical evidence on the use of the FLQ formula, Regional Studies, first published on 25 February 2013 (iFirst), doi:10.1080/00343404.2013.766318.

KRONENBERG T. (2009) Construction of regional input-output tables using nonsurvey methods: the role of cross-hauling, International Regional Science Review 32, 40-64.

KRONENBERG T. (2012) Regional input-output models and the treatment of imports in the European System of Accounts, Jahrbuch für Regionalwissenschaft (Review of Regional Research) 32, 175-191, Online First, doi: 10.1007/s10037-012-0065-2.

LEHTONEN O. and TYKKYLÄINEN M. (2012) Estimating regional input coefficients and multipliers: is the choice of a non-survey technique a gamble?, Regional Studies, first published on 1 March 2012 (iFirst), doi: 10.1080/00343404.2012.657619.

LOUHELA T. (2006). Estimation of interregional trade for Finnish regions in 1996 and 2002 - freight flow and gravity approaches, paper presented at the $46^{\text {th }}$ Congress of the European Regional Science Association, Velos, Greece, 30 August-3 September 2006.

Miller R. E. and BlaIR P. D. (2009) Input-Output Analysis: Foundations and Extensions, $2^{\text {nd }}$ edition. Cambridge University Press, Cambridge.

Statistics FinLAND (2000) Regional Input-Output 1995: Tables and Compilation Methods. Official 
Statistics of Finland, Helsinki.

Statistics Finland (2006) Regional Input-Output 2002 Tables. Statistics Finland, Helsinki.

Theil H., Beerens G.A.C., Deleeuw C.G. and Tilanus C.B. (1966), Applied Economic Forecasting, 15-43. Elsevier, New York.

Tонмо T. (2004) New developments in the use of location quotients to estimate regional input-output coefficients and multipliers, Regional Studies 38, 43-54. 
Table 1. Relative accuracy of alternative LQ-based methods for estimating type I output multipliers for Finnish regions in 2002 (Lehtonen and Tykkyyläinen's results)

\begin{tabular}{|c|c|c|c|c|c|c|c|c|c|c|}
\hline \multirow[b]{2}{*}{ Region } & \multicolumn{5}{|c|}{ SLQ } & \multicolumn{5}{|c|}{ CILQ } \\
\hline & STPE & E & $\mathrm{U}^{\mathrm{S}}$ & $\mathrm{U}^{\mathrm{M}}$ & $\begin{array}{c}\text { Mean } \\
\text { rank }\end{array}$ & $\mathrm{E}$ & M & $\mathrm{U}^{\mathrm{S}}$ & $\mathrm{U}^{\mathrm{M}}$ & $\begin{array}{c}\text { Mean } \\
\text { rank }\end{array}$ \\
\hline Ahvenanmaa & 8.718 & 0.163 & 0.109 & 1.054 & 2.00 & 14.397 & 0.136 & 0.056 & 9.548 & 2.75 \\
\hline Keski-Pohjanmaa & 8.513 & 0.137 & 0.137 & 5.214 & 2.50 & 11.564 & 0.103 & 0.022 & 6.425 & 3.00 \\
\hline Kainuu & 6.057 & 0.074 & 0.022 & 0.863 & 1.25 & 12.503 & 0.139 & 0.006 & 0.979 & 2.75 \\
\hline Etelä-Savo & 8.645 & 0.108 & \begin{tabular}{|l|}
0.062 \\
\end{tabular} & 4.665 & 3.00 & 12.749 & 29 & 0.022 & 7.388 & 3.50 \\
\hline Itä-Uusimaa & 11.130 & 0.162 & 0.045 & 15.708 & 3.00 & & 0.149 & 0.021 & $\mid 17.977$ & 3.00 \\
\hline Pohjois-Karjala & 6.472 & 0.087 & 0.009 & 3.836 & 1.25 & 9.520 & 0.104 & 0.006 & 3.867 & 2.50 \\
\hline Etelä-Pohjanmaa & 6.346 & 0.088 & 0.001 & 2.994 & 1.25 & 11.703 & 0.125 & 0.043 & 2.193 & 2.50 \\
\hline Kanta-Hän & 12.341 & 0.156 & 0.064 & 15.427 & 3.25 & 12.615 & 0.138 & 0.001 & 11.963 & 2.75 \\
\hline Etelä-Karjala & 12.309 & 0.156 & 0.086 & 13.540 & 4.00 & 12.181 & 0.118 & 0.015 & 11.140 & 2.50 \\
\hline Päijät-Häme & 9.968 & 0.129 & 0.044 & 11.469 & 2.50 & 13.076 & 0.149 & 0.028 & 6.788 & 2.25 \\
\hline Pohjanmaa & 10.233 & 0.155 & 0.039 & 6.778 & 4.00 & 10.073 & 0.127 & 0.004 & 5.919 & 2.25 \\
\hline Lappi & 8.077 & 119 & 0.000 & 4.951 & 3.00 & 11.302 & & 0.030 & 4.082 & 3.50 \\
\hline Poh & & & 0.028 & & & & & & & 2.25 \\
\hline Kyn & 13.268 & 55 & 0.126 & & 3.50 & & 52 & 0.084 & 12.536 & 3.25 \\
\hline Kesl & 7.183 & 986 & 0.021 & 5.386 & 2.75 & 9.814 & 111 & 0.009 & 7.111 & 3.25 \\
\hline Satal & 10.654 & 144 & 0.119 & 12.812 & 3.75 & 10.263 & .133 & 0.062 & 10.710 & 2.75 \\
\hline Pohjois-Pol & 5.384 & 0.083 & 0.013 & 1.307 & 1.50 & 10.545 & 0.109 & 0.008 & 4.548 & 2.75 \\
\hline Pirkanmaa & 11.233 & 137 & 0.010 & 12.818 & 2.25 & 11.830 & 0.127 & 0.027 & 8.760 & 2.25 \\
\hline Varsir & 10.403 & .144 & 0.022 & 7.464 & 3.50 & 10.737 & 0.137 & 0.001 & 4.076 & 2.25 \\
\hline Uusimaa & 5.485 & 065 & 0.093 & 6.013 & 2.00 & 9.308 & 00 & 0.056 & 2.102 & 2.25 \\
\hline \multirow[t]{2}{*}{ Mean } & 36 & 123 & 0.052 & 7.560 & 2.63 & 11.657 & 0.123 & 0.025 & 7.193 & 2.71 \\
\hline & \multicolumn{5}{|c|}{ FLQ } & \multicolumn{5}{|c|}{ RLQ } \\
\hline Ahve & 470 & 0.080 & 0.113 & .491 & 2.25 & 8.967 & 0.170 & 0.133 & 1.740 & 3.00 \\
\hline Keski-Pohjanr & 9.371 & 0.113 & 0.002 & 0.712 & 1.75 & 10.094 & 0.135 & 0.001 & 13.547 & 2.75 \\
\hline Kainuu & 9.276 & 0.126 & 0.079 & 7.907 & 3.25 & 8.443 & 0.096 & 0.059 & 10.718 & 2.75 \\
\hline & & 0.101 & 0.059 & & 1.75 & 7.014 & .095 & 0.001 & 6.680 & 1.75 \\
\hline & & & 0.0 & & 1. & & & 0.1 & 03 & 2.25 \\
\hline $\mathrm{Pol}$ & 79 & 04 & 0.088 & & 2.75 & 8.759 & 0.120 & 0.046 & & 3.50 \\
\hline Etelä-I & 8.856 & 129 & 0.168 & 3.406 & 3.00 & 10.392 & 0.148 & 0.036 & 15.211 & 3.25 \\
\hline Kanta-Häme & 7.021 & 0.071 & 0.093 & 0.299 & 1.75 & 9.815 & 0.119 & 0.065 & 11.330 & 2.25 \\
\hline Etelä-Karjala & 5.900 & 0.088 & 0.008 & 0.340 & 1.00 & 10.133 & 0.132 & 0.076 & 10.296 & 2.50 \\
\hline Päijät-Häme & 7.163 & 0.092 & 0.040 & 2.586 & 1.25 & 14.040 & 0.183 & 0.074 & 15.875 & 4.00 \\
\hline Pohjanmaa & 7.164 & 0.090 & 0.030 & 3.684 & 1.50 & 8.338 & 0.110 & 0.009 & 6.354 & 2.25 \\
\hline Lappi & 7.654 & 0.084 & 0.023 & 3.098 & 2.00 & 6.948 & 0.099 & 0.002 & 1.994 & 1.50 \\
\hline & & & 0.129 & & 2.00 & & & 0.063 & 14.667 & 3.50 \\
\hline & & & 0.004 & & 1.00 & 12.775 & 0.148 & 0.123 & 11.698 & 2.25 \\
\hline Keski-Suomi & 6.874 & 0.100 & 0.104 & 4.394 & 2.75 & 6.205 & 0.072 & 0.013 & 2.770 & 1.25 \\
\hline Satakunta & 5.131 & 0.067 & \begin{tabular}{|l|}
0.003 \\
\end{tabular} & 1.702 & 1.00 & 6.354 & 0.082 & 0.140 & 3.866 & 2.50 \\
\hline Pohjois-Pohj & 7.171 & 0.092 & 0.092 & 4.901 & 3.25 & 6.801 & 0.076 & 0.068 & 9.299 & 2.50 \\
\hline Pirkanmaa & 7.153 & 0.086 & 0.040 & 1.463 & 1.50 & 16.136 & 0.194 & 0.049 & 16.725 & 4.00 \\
\hline Varsin & 7.371 & 0.090 & 0.113 & 6.181 & 2.25 & 9.602 & 0.130 & 0.020 & 5.581 & 2.00 \\
\hline & 7.795 & 0.151 & \begin{tabular}{|l|}
$\mathbf{0 . 0 3 7}$ \\
\end{tabular} & 9.332 & 2.50 & 12.887 & 0.096 & 0.089 & 11.490 & 3.25 \\
\hline Mean & 7.181 & 0.096 & 0.066 & \begin{tabular}{|l|}
3.484 \\
\end{tabular} & 2.01 & 9.572 & 0.123 & 0.056 & 9.480 & 2.65 \\
\hline
\end{tabular}

Note: The best score is depicted in bold type and the second-best in italics. Mean rankings that are statistically significant at the 5\% level are shown in bold. 
Table 2. Relative accuracy of alternative LQ-based methods for estimating type I output multipliers for Finnish regions in 2002 (reworked)

\begin{tabular}{|c|c|c|c|c|c|c|c|c|c|c|}
\hline \multirow[b]{2}{*}{ Region } & \multicolumn{5}{|c|}{ SLQ } & \multicolumn{5}{|c|}{ CILQ } \\
\hline & STPE & MWAE & $\begin{array}{c}\tilde{\mathrm{U}}^{\mathrm{S}} \times \\
10^{3}\end{array}$ & $\begin{array}{c}\tilde{\mathrm{U}}^{\mathrm{M}} \times \\
10^{3}\end{array}$ & $\begin{array}{c}\text { Mean } \\
\text { rank }\end{array}$ & STPE & MWAF & $\begin{array}{c}\tilde{\mathrm{U}}^{\mathrm{S}} \times \\
10^{3}\end{array}$ & $\begin{array}{c}\tilde{\mathrm{U}}^{\mathrm{M}} \times \\
10^{3}\end{array}$ & $\begin{array}{c}\text { Mean } \\
\text { rank }\end{array}$ \\
\hline Ahvenanmaa & 8.325 & 2086 & 3.03 & 4.67 & 2.75 & 15.600 & 0.1715 & 4.81 & 31.41 & 3.50 \\
\hline Keski-Pohjanmaa & 10.501 & 0.1596 & 6.80 & 15.29 & 3.00 & 13.096 & 0.1232 & 2.70 & 24.72 & 3.00 \\
\hline Kainuu & 6.528 & \begin{tabular}{|l|}
0.0679 \\
\end{tabular} & 0.01 & 0.29 & 1.00 & 12.491 & 0.1359 & 0.63 & 8.47 & 3.75 \\
\hline Etelä-Savo & 9.595 & 0.1220 & 4.89 & 13.81 & 2.50 & 13.348 & 0.1312 & 4.06 & 26.45 & 3.75 \\
\hline Itä-Uusi & 11.156 & 0.1641 & 1.67 & 21.70 & 2.25 & 14.561 & & 2.38 & 37.55 & 4.00 \\
\hline Pohjois & 331 & 0.0994 & 1.26 & 9.36 & 2.50 & 9.793 & 0.1159 & 0.91 & 13.55 & 3.50 \\
\hline Etelä-P & 839 & \begin{tabular}{|l|}
$\mathbf{0 . 0 9 5 7}$ \\
\end{tabular} & 0.70 & 7.78 & 1.75 & 11.383 & 1312 & 1.23 & 10.79 & 3.50 \\
\hline Kanta-1 & 13.349 & 0.1737 & 4.23 & 32.38 & 3.00 & 14.233 & 0.1630 & 0.50 & 34.97 & 2.50 \\
\hline Etelä-K & 14.228 & 0.1909 & 8.61 & 37.28 & 4.00 & 13.468 & 0.1450 & 1.40 & 33.37 & 2.00 \\
\hline Päijät-Häme & 10.389 & 0.1454 & 3.23 & 20.24 & 2.25 & 14.475 & 0.1718 & 3.41 & 23.10 & 3.75 \\
\hline Pohjanmaa & 10.437 & \begin{tabular}{|l|}
0.1609 \\
\end{tabular} & 3.09 & 17.70 & 2.75 & 12.116 & 0.1605 & 1.64 & 18.69 & 3.00 \\
\hline Lappi & 9.461 & 0.1500 & 0.92 & 13.96 & 2.50 & 12.448 & 0.1454 & 2.71 & 17.94 & 3.50 \\
\hline Poh & 9.206 & 0.1299 & 2.44 & 14.74 & 3.00 & 10.024 & & 0.14 & 16.69 & 3.00 \\
\hline Kyn & 14.681 & & 12.95 & 38.43 & 3.00 & 7.461 & & 11.12 & 0.11 & 3.50 \\
\hline $\mathrm{K}$ & 140 & & 1.86 & 10.93 & .50 & & & 1.55 & 18.42 & .75 \\
\hline Sate & 12.155 & & 5.97 & 28.33 & 4.00 & 12.020 & 0.1669 & 3.60 & 23.24 & 2.25 \\
\hline Pohj & 943 & 0.0963 & 0.33 & 5.23 & 1.75 & 11.131 & 0.1309 & 1.57 & 16.60 & 4.00 \\
\hline Pirka & 11.751 & 504 & 2.08 & 26.86 & 2.25 & 13.702 & 0.1513 & 5.21 & 29.30 & 3.75 \\
\hline Vars & 11.245 & 0.1612 & 2.99 & 23.87 & 3.50 & 12.327 & 0.1598 & 1.69 & 17.84 & 3.00 \\
\hline Uusim & 4.006 & 0.0540 & 0.14 & 0.37 & 1.25 & 9.933 & 0.0784 & 6.48 & 9.87 & 3.75 \\
\hline \multirow[t]{2}{*}{ Mean } & 63 & & 3.36 & 17.16 & 2.58 & 12.710 & 455 & 2.89 & 23.15 & 3.34 \\
\hline & \multicolumn{5}{|c|}{ FLQ } & \multicolumn{5}{|c|}{ RLQ } \\
\hline & 52 & & 1.18 & 0.24 & 1.00 & & 08 & 2.05 & 2.52 & 2.75 \\
\hline Kes & 5.603 & 15 & 0.08 & 0.01 & 1.00 & 12.466 & 13 & 2.72 & 24.12 & 3.00 \\
\hline Kair & 8.065 & 0.1031 & 1.67 & 3.78 & 2.50 & 10.874 & 161 & 0.02 & 5.93 & 2.75 \\
\hline Etel & 5.339 & 0.0682 & 0.07 & 0.24 & 1.00 & 12.107 & 250 & 3.06 & 23.94 & 2.75 \\
\hline Itä-L & 4.271 & $\mathbf{0 . 0 5 6 3}$ & 0.48 & 0.59 & 1.00 & 14.023 & 0.1637 & 1.97 & 36.15 & 2.75 \\
\hline Pohjc & 5.541 & 0.0715 & 1.05 & 2.01 & 1.50 & 8.920 & 0.1103 & 0.57 & 13.27 & 2.50 \\
\hline Etelä & 6.547 & 0.0972 & 3.63 & 0.81 & 2.25 & 9.009 & 0.0957 & 0.67 & 12.12 & 2.50 \\
\hline Kan & 969 & & 1.15 & $\mathbf{0 . 0 3}$ & & 13.885 & 676 & 0.80 & 35.94 & 3.00 \\
\hline & & & 1.26 & 0.05 & & & & 1.91 & 36.17 & 3.00 \\
\hline Päija & 01 & 31 & 0.55 & 0.71 & 1.00 & 12.277 & 187 & 1.56 & 23.36 & 3.00 \\
\hline Pohjanmaa & 5.791 & 31 & 0.18 & 0.62 & 1.00 & 11.835 & 647 & 1.57 & 20.41 & 3.25 \\
\hline Lappi & 6.089 & 0.0694 & 0.08 & 0.29 & 1.00 & 11.633 & 0.1463 & 1.61 & 17.92 & 3.00 \\
\hline Pohjoi & 5.113 & \begin{tabular}{|l|}
0.0734 \\
\end{tabular} & 1.72 & 1.80 & 1.50 & 9.135 & 0.1222 & 0.23 & 16.81 & 2.50 \\
\hline Kymenlaakso & 6.594 & 0.0825 & 0.27 & 2.16 & 1.00 & 16.687 & 0.1707 & 10.04 & 49.37 & 2.50 \\
\hline Kes & 5.880 & 0.0799 & 0.92 & 1.15 & 1.00 & 9.971 & 0.1205 & 1.22 & 17.27 & 2.75 \\
\hline Sataku & 4.353 & \begin{tabular}{|l|}
0.0572 \\
\end{tabular} & & 0.01 & & 11.958 & 0.1683 & 4.11 & 27.33 & 2.75 \\
\hline Pohjois-Poh & 5.569 & 0.0726 & 0.74 & 0.91 & 1.50 & 9.742 & 230 & 0.66 & 14.07 & 2.75 \\
\hline Pirkanmaa & 6.182 & 0.0690 & 0.06 & 0.20 & & 12.973 & 0.1494 & 3.28 & 29.41 & 3.00 \\
\hline Varsinais-S & 6.033 & 0.0707 & 1.06 & 1.51 & 1.00 & 11.755 & 0.1578 & 1.25 & 20.06 & 2.50 \\
\hline Uusimaa & 6.456 & 0.1117 & $\mathbf{0 . 0 3}$ & 3.68 & 2.25 & 7.505 & 0.0677 & 1.58 & 4.49 & 2.75 \\
\hline Mean & 5.814 & 0.0762 & 0.81 & 1.04 & 1.30 & 11.692 & 0.1399 & 2.04 & 22.53 & 2.79 \\
\hline
\end{tabular}

Note: See note to Table 1. 
Table 3. Assessment of accuracy using different criteria: sectoral output multipliers for 20 Finnish regions in 2002 (unweighted)

\begin{tabular}{|l|r|c|c|c|c|c|}
\hline \multirow{2}{*}{ Method } & \multicolumn{6}{|c|}{ Criterion } \\
\cline { 2 - 7 } & STPE & MWAE & $\tilde{\mathrm{U}}^{\mathrm{S}} \times 10^{3}$ & $\tilde{\mathrm{U}}^{\mathrm{M}} \times 10^{3}$ & MPE & $\mathrm{U}$ \\
\hline SLQ & 9.76 & 0.1396 & 3.36 & 17.16 & 8.56 & 11.93 \\
\hline CILQ & 12.71 & 0.1445 & 2.89 & 23.15 & 11.04 & 15.41 \\
\hline FLQ & 5.81 & 0.0762 & 0.81 & 1.04 & -0.52 & 7.38 \\
\hline RLQ & 11.69 & 0.1399 & 2.04 & 22.53 & 10.70 & 13.96 \\
\hline
\end{tabular}

Table 4. Correlation coefficients between different measures of accuracy of the estimated FLQ-based multipliers for 20 Finnish regions in 2002

\begin{tabular}{|l|c|c|c|c|c||}
\hline \hline & STPE & MWAE & $\tilde{\mathrm{U}}^{\mathrm{S}}$ & $\tilde{\mathrm{U}}^{\mathrm{M}}$ & MPE \\
\hline MWAE & 0.720 & & & & \\
\hline$\tilde{\mathrm{U}}^{\mathrm{S}}$ & 0.272 & 0.364 & & & \\
\hline$\tilde{\mathrm{U}}^{\mathrm{M}}$ & 0.578 & 0.633 & 0.152 & & \\
\hline MPE & 0.118 & -0.160 & -0.037 & -0.066 & \\
\hline $\mathrm{U}$ & 0.547 & 0.367 & 0.119 & -0.027 & -0.328 \\
\hline
\end{tabular}


Table 5. Relative accuracy of alternative LQ-based methods for estimating input coefficients for Finnish regions in 2002 (reworked)

\begin{tabular}{|c|c|c|c|c|c|c|c|c|c|c|}
\hline \multirow[b]{2}{*}{ Region } & \multicolumn{5}{|c|}{ SLQ } & \multicolumn{5}{|c|}{ CILQ } \\
\hline & STPE & $\begin{array}{c}\text { MWAE } \\
\times 10^{2}\end{array}$ & $\begin{array}{l}\tilde{\mathrm{U}}^{\mathrm{S}} \times \\
10^{4}\end{array}$ & $\begin{array}{c}\tilde{\mathrm{U}}^{\mathrm{M}} \times \\
10^{4}\end{array}$ & $\begin{array}{c}\text { Mean } \\
\text { rank }\end{array}$ & STPE & $\begin{array}{l}\text { MWAE } \\
\times 10^{2}\end{array}$ & $\begin{array}{c}\tilde{\mathrm{U}}^{\mathrm{S}} \times \\
10^{4}\end{array}$ & $\begin{array}{c}\tilde{\mathrm{U}}^{\mathrm{M}} \times \\
10^{4}\end{array}$ & $\begin{array}{c}\text { Mean } \\
\text { rank }\end{array}$ \\
\hline Ahvenanmaa & .568 & 0.6297 & \begin{tabular}{|l|}
0.001 \\
\end{tabular} & 0.007 & 2.00 & 74.145 & 0.5408 & 0.416 & 0.119 & 3.50 \\
\hline Keski-Pohjanmaa & 50.687 & 0.4572 & 0.248 & 0.041 & 1.50 & 62.954 & 0.5172 & 0.615 & 0.085 & 4.00 \\
\hline Kainuu & 51.841 & 0.4974 & 0.124 & 0.000 & 1.50 & 64.213 & 0.5391 & 0.004 & 0.014 & 3.25 \\
\hline Etelä-Savo & 53.994 & 0.4668 & 0.269 & 0.038 & 2.00 & 60.470 & 0.5145 & 0.603 & .070 & 4.00 \\
\hline Itä-Uus & 66.078 & 0.5780 & 0.134 & 0.059 & 2.00 & 75.623 & 0.6056 & 0.409 & .115 & 4.00 \\
\hline Pohi & & & 0.128 & 0.021 & & & & 0.274 & & 75 \\
\hline Etelä- & & & 0.151 & 0.025 & & 58.915 & & 0.334 & 042 & \\
\hline Kant & .751 & 0.4824 & 0.281 & 0.091 & 00 & 60.406 & 130 & 0.450 & 103 & 3.75 \\
\hline Etelä & 60.197 & 0.5958 & 0.584 & 0.098 & .25 & 67.232 & .6014 & 0.669 & .105 & 3.75 \\
\hline Päijä & 49.910 & 0.4880 & 0.291 & 0.059 & 1.75 & 62.643 & .5663 & 0.542 & .066 & 3.75 \\
\hline Pohj & 50.751 & 0.5558 & 0.197 & 0.044 & 2.00 & 54.494 & .5786 & 0.345 & .050 & 3.75 \\
\hline Lapp & 51.049 & 0.4985 & 0.144 & 0.034 & 2.50 & 55.914 & 4931 & 0.265 & .049 & 3.75 \\
\hline Pohj & 44.590 & 0.4374 & 0.252 & 0.036 & 2.00 & 49.680 & & 0.335 & .043 & 3.75 \\
\hline & 819 & 0.5322 & 0.864 & 0.111 & & & & .326 & & 4.00 \\
\hline & & & 0.171 & & & & & & & \\
\hline & & & 0.341 & 0.069 & & & & .437 & & .25 \\
\hline & & 55 & \begin{tabular}{|l|}
0.062 \\
\end{tabular} & 0.013 & .50 & & & 0.251 & .044 & 4.00 \\
\hline Pirl & 47.172 & 0.4766 & 0.296 & 0.067 & .00 & 54.013 & 21 & 0.668 & .075 & 3.75 \\
\hline Var & 47.447 & 0.4844 & 0.109 & 0.050 & 50 & 49.017 & & 0.192 & 039 & 3.25 \\
\hline Uus & & 0.4645 & \begin{tabular}{|l|l|}
0.015 \\
\end{tabular} & 0.004 & 0 & & & 0.595 & 037 & 3.75 \\
\hline \multirow[t]{2}{*}{ Mean } & 934 & 0.4907 & 0.233 & 0.045 & 1.89 & 174 & 41 & 0.451 & .068 & 3.74 \\
\hline & \multicolumn{5}{|c|}{ FLQ } & \multicolumn{5}{|c|}{ RLQ } \\
\hline & 36 & 14 & 0.084 &  & 50 & 970 & & 0.173 & .085 & 3.00 \\
\hline & & & \begin{tabular}{|l|l}
003 \\
\end{tabular} & & & & & & & 3.00 \\
\hline & & & 0.249 & 0.026 & & & & .007 & & 2.75 \\
\hline & 14 & 62 & \begin{tabular}{|l|}
0.008 \\
\end{tabular} & 0.003 & 1.00 & 58.116 & 0.4 & 0.494 & .065 & 3.00 \\
\hline & 11 & 0.4440 & \begin{tabular}{|l|}
0.001 \\
\end{tabular} & 0.003 & 1.00 & 73.430 & 0.5868 & 0.345 & .109 & 3.00 \\
\hline & 801 & 0.4257 & \begin{tabular}{|l|l|}
0.001 \\
\end{tabular} & $\mathbf{0 . 0 1 0}$ & 1.50 & 49.987 & 0.4488 & 0.219 & .031 & 3.25 \\
\hline Etel & 51.106 & 0.4431 & \begin{tabular}{|l|}
0.011 \\
\end{tabular} & 0.002 & 1.75 & \begin{tabular}{|l|}
53.719 \\
\end{tabular} & 0.4310 & 0.270 & .046 & 3.00 \\
\hline & 49.427 & 0.4237 & \begin{tabular}{|l|}
0.001 \\
\end{tabular} & 0.000 & 1.00 & 57.035 & 0.4963 & 0.366 & .105 & 3.25 \\
\hline & & & \begin{tabular}{|l|l|}
0.020 \\
\end{tabular} & & & & 0.5872 & 0.600 & .111 & 3.00 \\
\hline & & & & & & & & 0.399 & .069 & 3.25 \\
\hline & & & & & & & & & & 3.25 \\
\hline & & & \begin{tabular}{|l|l|}
0.003 \\
\end{tabular} & & & & & 0.214 & 049 & 2.75 \\
\hline Pohj & 242 & 27 & \begin{tabular}{|l|l|}
0.002 \\
\end{tabular} & 0.008 & 1.00 & 47.420 & 0.4630 & 0.298 & .043 & 3.25 \\
\hline & 630 & 0.4540 & \begin{tabular}{|l|}
0.161 \\
\end{tabular} & 0.010 & 1.00 & 67.035 & 0.5416 & 1.180 & .158 & 3.00 \\
\hline Keski- & 844 & 0.4211 & \begin{tabular}{|l|}
0.000 \\
\end{tabular} & 0.005 & 1.25 & 48.567 & \begin{tabular}{|l|l}
0.4519 \\
\end{tabular} & 0.251 & .047 & 3.00 \\
\hline Sata & 564 & 0.4774 & \begin{tabular}{|l|l|}
$\mathbf{0 . 0 3 0}$ \\
\end{tabular} & $\mathbf{0 . 0 0 0}$ & 1.00 & 53.155 & 0.5443 & 0.439 & .068 & 3.25 \\
\hline Poh & 44.990 & 0.4203 & \begin{tabular}{|l|l|}
0.000 \\
\end{tabular} & 0.004 & 1.50 & 47.902 & \begin{tabular}{|l|l}
0.4569 \\
\end{tabular} & 0.177 & 0.039 & 3.00 \\
\hline & & & & & & 51.408 & 0.4893 & 0.509 & .076 & 3.25 \\
\hline & & & & & & & \begin{tabular}{|l|}
0.4937 \\
\end{tabular} & 0.150 & .044 & 3.25 \\
\hline & 46 & & 0.021 & 0.009 & & & 0.4781 & 0.192 & .017 & 2.75 \\
\hline Mean & 49.170 & 0.4534 & \begin{tabular}{|l}
0.034 \\
\end{tabular} & 0.005 & 1.31 & 56.177 & 0.5045 & 0.352 & 0.065 & 3.06 \\
\hline
\end{tabular}

Note: See note to Table 1. 
Table 6. Assessment of accuracy using different criteria: input coefficients for 20 Finnish regions in 2002 (unweighted)

\begin{tabular}{|l|c|c|c|c|c|c|}
\hline \multirow{2}{*}{ Method } & \multicolumn{6}{|c|}{ Criterion } \\
\cline { 2 - 7 } & STPE & MWAE $\times 10^{2}$ & $\tilde{\mathrm{U}}^{\mathrm{S}} \times 10^{4}$ & $\tilde{\mathrm{U}}^{\mathrm{M}} \times 10^{4}$ & MPE & $\mathrm{U}$ \\
\hline SLQ & 50.93 & 0.4907 & 0.2331 & 0.0449 & 263.1 & 0.5210 \\
\hline CILQ & 59.17 & 0.5241 & 0.4511 & 0.0677 & 239.5 & 0.6349 \\
\hline FLQ & 49.17 & 0.4534 & 0.0342 & 0.0048 & 180.7 & 0.4887 \\
\hline RLQ & 56.18 & 0.5045 & 0.3515 & 0.0653 & 251.5 & 0.5832 \\
\hline \hline
\end{tabular}


Table 7. Relative accuracy of alternative LQ-based methods for estimating input coefficients for Finnish regions in 2002 (Lehtonen and Tykkyyläinen's results)

\begin{tabular}{|c|c|c|c|c|c|c|c|c|c|c|}
\hline \multirow[b]{2}{*}{ Region } & \multicolumn{5}{|c|}{ SLQ } & \multicolumn{5}{|c|}{$\overline{\text { CILQ }}$} \\
\hline & STPE & MWAE & $\mathrm{U}^{\mathrm{S}}$ & $\mathrm{U}^{\mathrm{M}}$ & $\begin{array}{c}\text { Mean } \\
\text { rank }\end{array}$ & TPF & MWAE & $\mathrm{U}^{\mathrm{S}}$ & $\mathrm{U}^{\mathrm{M}}$ & $\begin{array}{c}\text { Mean } \\
\text { rank }\end{array}$ \\
\hline Ahvenanmaa & 50.001 & 156 & 0.005 & 0.000 & 2.00 & 64.951 & 0.117 & 0.068 & 0.022 & 3.00 \\
\hline Keski-Pohjan & 34.935 & 097 & 0.133 & 0.010 & 2.00 & & & & & \\
\hline Kainuu & $\mathbf{3 4 . 3 2 2}$ & & 0.083 & & 2.00 & 50.192 & & 0.003 & & 2.25 \\
\hline Etelä-Savo & 37.948 & 101 & \begin{tabular}{|l|}
0.100 \\
\end{tabular} & 0.008 & 2.00 & 45.408 & .112 & 0.176 & 0.016 & 3.75 \\
\hline Itä-Uusimaa & 54.223 & 143 & 0.070 & 0.024 & 2.75 & 59.991 & 0.145 & 0.120 & 0.033 & 4.00 \\
\hline Pohjois-K & 28.179 & 0.080 & 0.056 & 0.005 & 1.50 & 35.803 & 0.097 & 0.083 & 0.005 & 3.00 \\
\hline Etelä-Pohjann & 3.510 & $\mathbf{0 . 0 8 3}$ & 0.081 & 0.005 & 1.25 & 47.420 & 0.105 & 0.085 & 0.007 & 2.75 \\
\hline Kanta-Häme & 40.655 & 0.097 & 0.183 & 0.047 & 2.50 & 47.086 & 0.103 & 0.152 & 0.031 & 3.00 \\
\hline Etelä-Karjala & 43.447 & 0.105 & 0.221 & 0.032 & 2.75 & 49.730 & 0.111 & 0.178 & 0.025 & 3.00 \\
\hline Päijät-H & & & \begin{tabular}{|l|}
0.199 \\
\end{tabular} & & 2.25 & & & & & 2.75 \\
\hline Poh & & & & & & & & & & \\
\hline Lap & 856 & & 37 & 7 & 2.50 & & & 0.062 & 0.009 & 3.00 \\
\hline Pohj & .186 & 0.089 & 139 & 0.012 & 2.25 & & 03 & 0.135 & 0.011 & 2.75 \\
\hline & .668 & 0.102 & 0.370 & 0.042 & 3.00 & 388 & 114 & 0.383 & 0.041 & 3.75 \\
\hline Kesk & .581 & 0.079 & 0.098 & 0.011 & 1.75 & & 0.093 & 0.138 & 0.018 & 3.50 \\
\hline Satak & 3.231 & 0.099 & 0.236 & 0.038 & 3.00 & 220 & 0.108 & 0.230 & 0.024 & 3.00 \\
\hline Pohj & 3.420 & 0.081 & \begin{tabular}{|l|}
0.012 \\
\end{tabular} & 0.001 & 1.00 & 577 & 0.101 & 0.069 & 0.009 & 3.00 \\
\hline Pirka & 3.775 & 0.090 & 0.169 & 0.028 & 2.00 & 736 & 0.096 & 0.225 & .020 & 2.75 \\
\hline Var & 62 & 93 & 0.021 & & 2.25 & & & & & 2.75 \\
\hline & & & & & & & & & & 25 \\
\hline \multirow[t]{2}{*}{ Mean } & & & \begin{tabular}{|l|}
0.117 \\
\end{tabular} & 0.017 & 2.14 & & 0.107 & 0.139 & 0.017 & 3.05 \\
\hline & \multicolumn{5}{|c|}{ FLQ } & \multicolumn{5}{|c|}{ RLQ } \\
\hline $\mathrm{Ah}$ & & 0.129 & \begin{tabular}{|l|}
0.089 \\
\end{tabular} & 0.004 & 2.75 & & .136 & 0.002 & .001 & 2.25 \\
\hline Kes & 610 & & & & 1.75 & & & 0.044 & .004 & 2.75 \\
\hline & & & & & & & & & & 2.75 \\
\hline & & & & & & & & & & 1.25 \\
\hline Itä- & 161 & 35 & \begin{tabular}{|l|}
0.000 \\
\end{tabular} & 0.000 & 1.25 & 711 & 0.128 & 0.023 & 0.027 & 2.00 \\
\hline Poh & 266 & 0.110 & \begin{tabular}{|l|}
0.007 \\
\end{tabular} & 0.025 & 2.50 & 34.439 & 0.102 & 0.042 & 0.041 & 3.00 \\
\hline Etelä-F & 43.622 & 0.140 & \begin{tabular}{|l|l|}
0.000 \\
\end{tabular} & 0.008 & 2.75 & 41.050 & 0.121 & 0.085 & 0.032 & 3.25 \\
\hline Kanta-Häme & 41.221 & 0.114 & \begin{tabular}{|l|}
0.000 \\
\end{tabular} & 0.001 & 2.25 & $\mathbf{3 7 . 2 3 8}$ & 0.102 & 0.123 & 0.070 & 2.25 \\
\hline Etelä-K & 36.434 & & \begin{tabular}{|l|}
0.010 \\
\end{tabular} & 0.001 & 1.75 & 41.072 & 0.107 & 0.177 & 0.097 & 2.50 \\
\hline & & & \begin{tabular}{|l|}
0.000 \\
\end{tabular} & 0.005 & 2.50 & 41.429 & 0.127 & 0.313 & 0.003 & 2.50 \\
\hline Poh & & & & & 2.25 & & & 0.013 & & 2.25 \\
\hline Lap & & & & & & & & & & \\
\hline & & & & 0.026 & 2.75 & & & 0.085 & & 2.25 \\
\hline Kyme & 37.746 & 0.110 & \begin{tabular}{|l|}
0.074 \\
\end{tabular} & 0.001 & 1.50 & 43.776 & 0.102 & 0.362 & 0.002 & 1.75 \\
\hline Keski-Suomi & 31.707 & 0.103 & \begin{tabular}{|l|}
0.008 \\
\end{tabular} & 0.014 & 2.50 & 27.286 & 0.080 & 0.075 & 0.039 & 2.25 \\
\hline Satakunta & 33.756 & 0.118 & \begin{tabular}{|l|l|}
0.005 \\
\end{tabular} & 0.007 & 2.25 & 29.232 & 0.098 & 0.089 & 0.028 & 1.75 \\
\hline Pohjo & 35.280 & 0.103 & 0.027 & 0.017 & 3.50 & 29.572 & 0.081 & 0.025 & 0.108 & 2.50 \\
\hline Pirka & 37.079 & & \begin{tabular}{|l|l|}
0.005 \\
\end{tabular} & 0.003 & 1.75 & 38.186 & 0.123 & 0.336 & 0.027 & 3.50 \\
\hline Var: & 32.594 & 0.112 & 0.093 & 0.023 & 3.75 & 29.382 & 0.092 & 0.012 & 0.008 & 1.25 \\
\hline Uusi & & & & & 2.75 & & 0.099 & 0.205 & 0.028 & 3.25 \\
\hline Mean & 38.569 & 0.118 & \begin{tabular}{|l|}
0.025 \\
\end{tabular} & 0.010 & 2.45 & 37.558 & 0.107 & 0.110 & 0.035 & 2.36 \\
\hline
\end{tabular}

Note: See note to Table 1. 
Table 8. Alternative estimates of $\delta$ for Finnish regions

\begin{tabular}{|l|c|c|c|}
\hline & $\begin{array}{c}\delta^{*} \\
1995\end{array}$ & $\begin{array}{c}\delta^{*} \\
2002\end{array}$ & $\begin{array}{c}\text { Equation } \\
(25)\end{array}$ \\
\hline Ahvenanmaa & 0.125 & 0.099 & 0.109 \\
\hline Keski-Pohjanmaa & 0.198 & 0.096 & 0.091 \\
\hline Kainuu & 0.185 & 0.039 & 0.092 \\
\hline Etelä-Savo & 0.242 & 0.098 & 0.109 \\
\hline Itä-Uusimaa & 0.412 & 0.115 & 0.093 \\
\hline Pohjois-Karjala & 0.242 & 0.071 & 0.109 \\
\hline Etelä-Pohjanmaa & 0.180 & 0.089 & 0.115 \\
\hline Kanta-Häme & 0.283 & 0.124 & 0.111 \\
\hline Etelä-Karjala & 0.259 & 0.115 & 0.103 \\
\hline Päijät-Häme & 0.245 & 0.098 & 0.117 \\
\hline Pohjanmaa & 0.241 & 0.096 & 0.114 \\
\hline Lappi & 0.209 & 0.100 & 0.113 \\
\hline Pohjois-Savo & 0.243 & 0.089 & 0.122 \\
\hline Kymenlaakso & 0.306 & 0.161 & 0.115 \\
\hline Keski-Suomi & 0.272 & 0.098 & 0.125 \\
\hline Satakunta & 0.338 & 0.134 & 0.123 \\
\hline Pohjois-Pohjanmaa & 0.263 & 0.109 & 0.140 \\
\hline Pirkanmaa & 0.366 & 0.140 & 0.151 \\
\hline Varsinais-Suomi & 0.307 & 0.116 & 0.150 \\
\hline Uusimaa & 0.383 & 0.000 & 0.244 \\
\hline Unweighted mean & 0.265 & 0.099 & 0.122 \\
\hline Weighted mean & 0.310 & 0.076 & 0.163 \\
\hline
\end{tabular}

Note: The weighted means are based on regional employment in 2002. 
Table 9. Average import propensities and output multipliers for Finnish regions

\begin{tabular}{||l|c|c|c|c|c|c|c|c||}
\hline & \multicolumn{9}{|c|}{$\begin{array}{c}\text { Mean proportion of gross output imported } \\
\text { from other regions }\end{array}$} & \multicolumn{3}{c|}{ Mean type I output multiplier } \\
\hline & $\begin{array}{c}1995 \\
\mathrm{n}=37\end{array}$ & $\begin{array}{c}2002 \\
\mathrm{n}=26\end{array}$ & $\begin{array}{c}2002- \\
1995\end{array}$ & $\begin{array}{c}\text { Difference } \\
(\%)\end{array}$ & $\begin{array}{c}1995 \\
\mathrm{n}=37\end{array}$ & $\begin{array}{c}2002 \\
\mathrm{n}=26\end{array}$ & $\begin{array}{c}2002- \\
1995\end{array}$ & $\begin{array}{c}\text { Difference } \\
(\%)\end{array}$ \\
\hline Ahvenanmaa & 0.1796 & 0.1677 & -0.0119 & -6.6 & 1.281 & 1.321 & 0.040 & 3.1 \\
\hline Keski-Pohjanmaa & 0.1814 & 0.1175 & -0.0639 & -35.2 & 1.271 & 1.366 & 0.095 & 7.4 \\
\hline Kainuu & 0.1749 & 0.1364 & -0.0385 & -22.0 & 1.253 & 1.389 & 0.136 & 10.8 \\
\hline Etelä-Savo & 0.1926 & 0.1192 & -0.0734 & -38.1 & 1.217 & 1.361 & 0.144 & 11.9 \\
\hline Itä-Uusimaa & 0.2361 & 0.1169 & -0.1193 & -50.5 & 1.168 & 1.356 & 0.188 & 16.1 \\
\hline Pohjois-Karjala & 0.1854 & 0.0994 & -0.0861 & -46.4 & 1.249 & 1.418 & 0.169 & 13.5 \\
\hline Etelä-Pohjanmaa & 0.1771 & 0.1167 & -0.0604 & -34.1 & 1.280 & 1.380 & 0.100 & 7.8 \\
\hline Kanta-Häme & 0.2038 & 0.1090 & -0.0948 & -46.5 & 1.251 & 1.367 & 0.116 & 9.3 \\
\hline Etelä-Karjala & 0.1780 & 0.1196 & -0.0584 & -32.8 & 1.257 & 1.372 & 0.115 & 9.1 \\
\hline Päijät-Häme & 0.2011 & 0.0931 & -0.1080 & -53.7 & 1.243 & 1.387 & 0.144 & 11.6 \\
\hline Pohjanmaa & 0.2025 & 0.1041 & -0.0983 & -48.6 & 1.286 & 1.431 & 0.145 & 11.3 \\
\hline Lappi & 0.1598 & 0.1272 & -0.0325 & -20.4 & 1.305 & 1.395 & 0.090 & 6.9 \\
\hline Pohjois-Savo & 0.1795 & 0.0962 & -0.0833 & -46.4 & 1.286 & 1.420 & 0.134 & 10.4 \\
\hline Kymenlaakso & 0.1917 & 0.1332 & -0.0586 & -30.5 & 1.250 & 1.345 & 0.095 & 7.6 \\
\hline Keski-Suomi & 0.1913 & 0.0978 & -0.0935 & -48.9 & 1.263 & 1.419 & 0.156 & 12.3 \\
\hline Satakunta & 0.1873 & 0.1127 & -0.0746 & -39.8 & 1.242 & 1.402 & 0.160 & 12.9 \\
\hline Pohjois-Pohjanmaa & 0.1728 & 0.1007 & -0.0721 & -41.7 & 1.303 & 1.419 & 0.116 & 8.9 \\
\hline Pirkanmaa & 0.1977 & 0.0850 & -0.1127 & -57.0 & 1.236 & 1.421 & 0.185 & 15.0 \\
\hline Varsinais-Suomi & 0.1824 & 0.0780 & -0.1043 & -57.2 & 1.274 & 1.448 & 0.174 & 13.7 \\
\hline Uusimaa & 0.1654 & 0.0925 & -0.0729 & -44.1 & 1.334 & 1.469 & 0.135 & 10.1 \\
\hline Unweighted mean & 0.1870 & 0.1111 & -0.0759 & -40.0 & 1.262 & 1.394 & 0.132 & 10.5 \\
\hline Weighted mean & 0.1805 & 0.0999 & -0.0805 & -44.3 & 1.285 & 1.425 & 0.140 & 10.9 \\
\hline
\end{tabular}

Note: The weighted means are based on regional employment in 2002. Source: Authors' calculations based on data from Statistics Finland. 
Table 10. Correlation coefficients between regional attributes and the ranks achieved by the $S L Q$ and FLQ in estimating regional multipliers: data for 20 Finnish regions in 2002

\begin{tabular}{|l|c|c|c|c|}
\hline & Method & $\begin{array}{c}\text { Herfindahl's } \\
\text { index of } \\
\text { specialization }\end{array}$ & $\begin{array}{c}\text { Theil's index } \\
\text { of } \\
\text { specialization }\end{array}$ & $\begin{array}{c}\text { Distance from } \\
\text { Helsinki }\end{array}$ \\
\hline $\begin{array}{l}\text { Original ranks } \\
\text { (Table1) }\end{array}$ & SLQ & -0.427 & -0.361 & -0.323 \\
\cline { 2 - 5 } & FLQ & 0.340 & 0.182 & 0.423 \\
\hline $\begin{array}{l}\text { Revised ranks } \\
\text { (Table 2) }\end{array}$ & SLQ & -0.401 & -0.306 & -0.216 \\
\cline { 2 - 6 } & FLQ & 0.247 & 0.122 & 0.083 \\
\hline
\end{tabular}




\section{Recent UWE Economics Papers}

See http://www1.uwe.ac.uk/bl/bbs/bbsresearch/economics/economicspapers.aspx for a full list

\section{$\underline{2013}$}

1315 Global economic crisis and corruption experience: Evidence from transition economies Artjoms Ivlevs and Timothy Hinks

1314 A two-state Markov-switching distinctive conditional variance application for tanker freight returns Wessam Abouarghoub, Iris Biefang-Frisancho Mariscal and Peter Howells

1313 Measuring the level of risk exposure in tanker shipping freight markets Wessam Abouarghoub and Iris Biefang-Frisancho Mariscal

1312 Modelling the sectoral allocation of labour in open economy models Laura Povoledo

1311 The US Fed and the Bank of England: ownership, structure and 'independence' Peter Howells

1310 Cross-hauling and regional input-output tables: the case of the province of Hubei, China Anthony T. Flegg, Yongming Huang and Timo Tohmo

1309 Temporary employment, job satisfaction and subjective well-being Chris Dawson and Michail Veliziotis

1308 Risk taking and monetary policy before the crisis: the case of Germany Iris Biefang-Frisancho Mariscal

1307 What determines students' choices of elective modules? Mary R Hedges, Gail A Pacheco and Don J Webber

1306 How should economics curricula be evaluated? Andrew Mearman

1305 Temporary employment and wellbeing: Selection or causal? Chris Dawson, Don J Webber and Ben Hopkins

1304 Trade unions and unpaid overtime in Britain Michail Veliziotis

1303 Why do students study economics? Andrew Mearman, Aspasia Papa and Don J. Webber

1302 Estimating regional input coefficients and multipliers: The use of the FLQ is not a gamble Anthony T. Flegg and Timo Tohmo

1301 Liquidity and credit risks in the UK's financial crisis: How QE changed the relationship Woon Wong, Iris Biefang-Frisancho Mariscal, Wanru Yao and Peter Howells

1221 The impact of the quality of the work environment on employees' intention to quit Ray Markey, Katherine Ravenswood and Don J. Webber

1220 The changing influence of culture on job satisfaction across Europe: 1981-2008

Gail Pacheco, De Wet van der Westhuizen and Don J. Webber 
1219 Understanding student attendance in Business Schools: an exploratory study Andrew Mearman, Don J. Webber, Artjoms Ivḷevs, Tanzila Rahman \& Gail Pacheco

1218 What is a manufacturing job?

Felix Ritchie, Andrew D. Thomas and Richard Welpton

1217 Rethinking economics: Logical gaps - empirical to the real world Stuart Birks

1216 Rethinking economics: Logical gaps - theory to empirical Stuart Birks

1215 Rethinking economics: Economics as a toolkit Stuart Birks

1214 Rethinking economics: Downs with traction Stuart Birks

1213 Rethinking economics: theory as rhetoric Stuart Birks

1212 An economics angle on the law Stuart Birks

1211 Temporary versus permanent employment: Does health matter? Gail Pacheco, Dominic Page and Don J. Webber

1210 Issues in the measurement of low pay: 2010 Suzanne Fry and Felix Ritchie

1209 Output-based disclosure control for regressions Felix Ritchie

1208 Sample selection and bribing behaviour Timothy Hinks and Artjoms Ivlevs

1207 Internet shopping and Internet banking in sequence Athanasios G. Patsiotis, Tim Hughes and Don J. Webber

1206 Mental and physical health: Reconceptualising the relationship with employment propensity Gail Pacheco, Dom Page and Don J. Webber

1205 Using student evaluations to improve individual and department teaching qualities Mary R. Hedges and Don J. Webber

1204 The effects of the 2004 Minority Education Reform on pupils' performance in Latvia Artjoms Ivlevs and Roswitha M. King

1203 Pluralist economics curricula: Do they work and how would we know? Andrew Mearman

1202 Fractionalization and well-being: Evidence from a new South African data set Timothy Hinks

1201 The role of structural change in European regional productivity growth Eoin O'Leary and Don J. Webber 